\title{
Bone resorption induced by parathyroid hormone is strikingly diminished in collagenase-resistant mutant mice
}

\author{
Weiguang Zhao, ${ }^{1}$ Michael H. Byrne, ${ }^{1}$ Brendan F. Boyce, ${ }^{2}$ and Stephen M. Krane ${ }^{1}$ \\ ${ }^{1}$ Department of Medicine, Harvard Medical School, Medical Services (Arthritis Unit), Massachusetts General Hospital, Boston, \\ Massachusetts 02114, USA \\ ${ }^{2}$ Department of Pathology, University of Texas Health Science Center at San Antonio, San Antonio, Texas 78284, USA \\ Address correspondence to: Stephen M. Krane, Arthritis Unit/Bulf 165, Massachusetts General Hospital, 55 Fruit Street, Boston, \\ Massachusetts 02114, USA. Phone: (617) 726-2870; Fax (617) 726-2872; E-mail: krane.stephen@mgh.harvard.edu \\ Received for publication October 12, 1998, and accepted in revised form January 5, 1999.
}

\begin{abstract}
Parathyroid hormone (PTH) stimulates bone resorption by acting directly on osteoblasts/stromal cells and then indirectly to increase differentiation and function of osteoclasts. PTH acting on osteoblasts/stromal cells increases collagenase gene transcription and synthesis. To assess the role of collagenase in the bone resorptive actions of PTH, we used mice homozygous $(\mathrm{r} / \mathrm{r})$ for a targeted mutation $(\mathrm{r})$ in Col1a1 that are resistant to collagenase cleavage of type I collagen. Human PTH(1-34) was injected subcutaneously over the hemicalvariae in wild-type $(+/+)$ or $\mathrm{r} / \mathrm{r}$ mice four times daily for three days. Osteoclast numbers, the size of the bone marrow spaces and periosteal proliferation were increased in calvariae from PTH-treated $+/+$ mice, whereas in $\mathrm{r} / \mathrm{r}$ mice, PTH-induced bone resorption responses were minimal. The $\mathrm{r} / \mathrm{r}$ mice were not resistant to other skeletal effects of PTH because abundant interstitial collagenase mRNA was detected in the calvarial periosteum of PTH-treated, but not vehicle-treated, $r / r$ and $+/+$ mice. Calcemic responses, 0.5-10 hours after intraperitoneal injection of $\mathrm{PTH}$, were blunted in $\mathrm{r} / \mathrm{r}$ mice versus $+/+$ mice. Thus, collagenase cleavage of type I collagen is necessary for PTH induction of osteoclastic bone resorption.
\end{abstract}

J. Clin. Invest. 103:517-524 (1999).

\section{Introduction}

Parathyroid hormone (PTH) induces hypercalcemia in part through increasing bone resorption mediated by osteoclasts. Receptors for PTH are present not on osteoclasts, however, but on mesenchymal cells of the osteoblast lineage and stromal cells in the bone marrow (1). PTH must therefore act directly on these mesenchymal cells, which then - through direct cell-cell contact mediated by cellbound ligands such as osteoclast differentiation factor (ODF) and/or production of soluble ligands - modulates the activity of existing osteoclasts and the differentiation of osteoclasts from precursor cells $(2,3)$.

Shortly after the discovery of the animal collagenases by Gross and Lapière (4), Walker et al. (5) found that bones removed from mice injected with doses of PTH sufficient to elevate serum calcium levels by $\sim 4 \mathrm{mg} / \mathrm{dl}$ produce collagenase activity at levels much higher than in bones removed from uninjected mice. The time course of the effects on inducing hypercalcemia and collagenase production was different in that increased collagenase production was not detected until several hours after serum calcium levels reached their peak (6). It had also been shown that the sustained hypercalcemia induced by PTH was obviated by inhibitors of mRNA synthesis (actinomycin D) $(7,8)$ or protein synthesis (puromycin) (9), suggesting that, at least in part, PTH-induced hypercalcemia is dependent upon the synthesis of a protein in bone; collagenase was a candidate. In subsequent studies from several laboratories it was shown that in organ cultures of bone fragments, collagenase was released into the ambient medium and collagenase production could be stimulated by PTH (10-14). Later, it was possible to clone a collagenase gene from a cDNA library prepared from a rat osteogenic sarcoma cell line stimulated with PTH (15). A mouse collagenase cDNA was subsequently cloned (16) using the rat cDNA probe (15), and it was determined that the rodent enzymes had only $\sim 50 \%$ amino acid sequence similarity to human collagenase- 1 (matrix metalloproteinase-1 [MMP-1]) but had high similarity to what was later identified as collagenase-3 (MMP-13) in humans (17). Osteoclasts, in addition to producing cysteine proteinases, also produce MMPs such as the $92-k D a$ gelatinase (gelatinase B) (18) and one of the membrane-bound (MT) MMPs, MT1-MMP (19). In all but a few reported studies (e.g., ref. 20), however, it has not been possible to identify the expression of specific collagenases in osteoclasts using cDNA or cRNA probes. In contrast, several investigators have been readily able to measure collagenase produced by osteoblasts or stromal fibroblasts from different species, as described above, either constitutively or induced by several ligands, including PTH. When osteoblasts are exposed to PTH, they start producing collagenase and stop synthesizing collagen (21).

During normal embryonic development, collagenase is expressed in cells (osteoblasts, stromal cells) in the bone shaft and in hypertrophic chondrocytes of the distal growth plate (22-25). More proximal hypertrophic chondrocytes that characteristically express type $\mathrm{X}$ collagen do not express collagenase. Furthermore, the expression of collagenase (26) 
assayed by in situ hybridization is reduced, although not absent, in the distal growth plate and midshafts of bones from PTH/PTHrP receptor-null (-/-) mouse embryos (27). These observations imply that PTH and/or PTHrP could be important in regulation of collagenase expression, and therefore of resorption of the extracellular matrix (ECM) of distal growth plate calcified cartilage and bone during development. It has been suggested, based on assessments of osteoclast attachment and pit formation in in vitro assays, that collagenase produced by osteoblasts in remodeling bone acts on the layer of hypomineralized collagen on bone surfaces to permit osteoclasts to attach and then resorb bone by other mechanisms as described previously (28). Thus, chondrocytes and osteoblasts (or possibly related mesenchymal cells), which at some stage function to synthesize the ECM of cartilage and bone, also could function at another stage (in bone resorption) by preparing the matrix for osteoclastic attachment and subsequent degradation by cathepsins that act at acid $\mathrm{pH}$.

To understand the role of collagenase in remodeling of type I collagen-containing tissues, we have generated mice (Col1 $\left.1^{\mathrm{tml} J a e}\right)$ that have a targeted mutation(r) in the Col1a1 gene that encodes amino acid substitutions in the $\alpha 1$ (I) chains that induce resistance to cleavage in the helical domain by collagenases $(29,30)$. In this study, we have used these mice to further define mechanisms underlying the osteoclastic bone resorption induced by PTH. Here, we have used the models of Boyce et al. (31) and Yates et al. (32), in which PTH is injected over one-half of the calvariae four times daily for three days, and the calvariae are removed and examined histologically. In the calvariae of 4-, 6-, and 40-week-old wild-type (+/+) mice injected with $\mathrm{PTH}$, we observed marked bone resorption and enlarged marrow spaces with prominent osteoclasts. In contrast, in homozygous $(\mathrm{r} / \mathrm{r})$ mice of similar age, resorption inside the calvariae in response to $\mathrm{PTH}$ was strikingly decreased compared with $+/+$ mice, and few

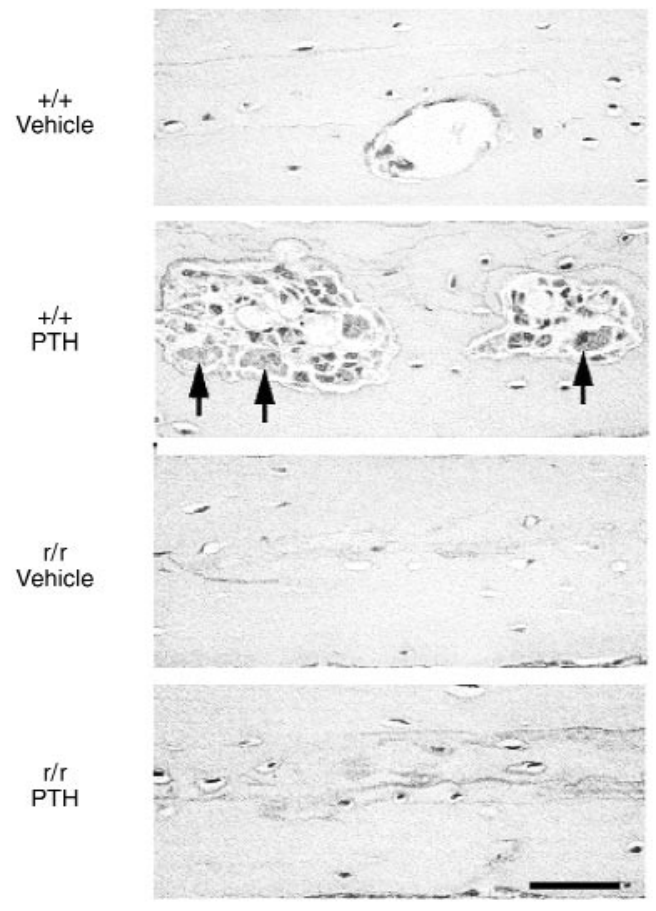

osteoclasts were identified. In both groups of animals, however, collagenase was induced in osteoblasts and fibroblastic cells in the periosteum as assessed by in situ hybridization with collagenase riboprobes. Collagenase must therefore have a critical role in mediating the acute osteoclastic bone resorption induced by PTH, in vivo.

\section{Methods}

Mice. To obtain sufficient $\mathrm{r} / \mathrm{r}$ mice for the experiments to be described, we chose to use the progeny of $\mathrm{r} / \mathrm{r}$ breeding pairs of the Col1a $1^{\text {tml Jae }}$ mice. Homozygous offspring were genotyped using a PCR-based method (see below) rather than by the more tedious method of Southern analysis reported previously (30). Wild-type $(+/+)$ controls comprised C57BL/6, 129 strain, from which the J1 embryonic stem cells were derived, as well as the $+/+$ progeny of $\mathrm{r} /+$ (heterozygous) breeding pairs.

Genotyping. We developed a rapid, nested PCR method with genomic DNA as template for genotyping. The DNA Thermal Cycler from Perkin-Elmer Corp. (Norwalk, Connecticut, USA) was used. We took advantage of changes in DNA sequence in the mutant IV construct (29) used for gene targeting in the Colla $1^{\text {tml Jae }}$ mice. In the mutant construct, a downstream KpnI site (within an intron) was destroyed but the KpnI site in exon 40 , where the amino acids surrounding the collagenase cleavage site are encoded in Col1a1, was retained and a new SphI site was introduced in exon 40. First-round PCR was carried out using 1 $\mu \mathrm{g}$ of genomic DNA, a forward oligonucleotide primer in intron 35 (5'-TGAGACACGAGGCATGGGACC-3') and a reverse primer in intron 43 (5'-GCATGTCTGAAGAAGAGGTCT-3') to obtain sufficient amplified DNA. Second-round PCR was carried out using the first-round product as template with a forward oligonucleotide primer in intron 38 (5'-GTGAGTATCTGTGGTTCTGGA-3') and a reverse primer in intron 41 (5'-CAGGGGGACTGGCTAGGAGGT-3'). Conditions were as follows: genomic DNA $(\sim 1 \mu \mathrm{g} / \mathrm{ml}), 1.0 \mu \mathrm{l}$, as template for the first round; primers $(50 \mathrm{mM}), 0.5 \mu \mathrm{l}$ of each; $5 \times$ PCR buffer (Tris$\mathrm{HCl}[\mathrm{pH} 8.5,300 \mathrm{mM}]$ and $\left.\left[\mathrm{NH}_{2}\right] \mathrm{SO}_{4},[75 \mathrm{mM}]\right), 10.0 \mu \mathrm{l} ; \mathrm{MgCl}_{2}$ $(25 \mathrm{mM}), 4.0 \mu \mathrm{l}$; dNTP mixture $(2.5 \mathrm{mM}), 5.0 \mu \mathrm{l}$; sterile water to a total volume of $50 \mu \mathrm{l}$. Template for the second round was $1 \mu \mathrm{l}$ of first-round product. The above samples were denatured for 2 min at $97^{\circ} \mathrm{C}$. After reducing block temperature to $90^{\circ} \mathrm{C}, 1 \mu \mathrm{l}$ of Taq polymerase ( $5 \mathrm{U} / \mu \mathrm{l}$; Fisher Scientific, Pittsburgh, Pennsylvania, USA) was added to achieve a "hot start." Temperatures were then $94^{\circ} \mathrm{C}$ for $30 \mathrm{~s}, 62^{\circ} \mathrm{C}$ for $40 \mathrm{~s}, 72^{\circ} \mathrm{C}$ for 2 min for 35 cycles, followed by a final extension time of $5 \mathrm{~min}$ at $72^{\circ} \mathrm{C}$. Restriction enzymes were obtained from Promega Corp. (Madison, Wisconsin, USA). For restriction enzyme (Promega Corp.) digestion, $6.0 \mu \mathrm{l}$ of the second-round PCR product was incubated with $0.5 \mu$ l of either $S p h \mathrm{I}$ or KpnI at $10 \mathrm{U} / \mu \mathrm{l}$, with $2.0 \mu \mathrm{l}$ of the appropriate $10 \times$ buffer in a total volume of $20.0 \mu \mathrm{l}$. The predicted size, in bp, of the digestion products is: $S p h \mathrm{I}+/+, 986 ; S p h \mathrm{I}$ r/r, 562,428; KpnI +/+, 409, 360, 217; KpnI r/r, 581, 409. When-

\footnotetext{
Figure 1

Paraffin sections stained with $\mathrm{H} \& \mathrm{E}$ staining of calvarial bone from $+/+$ and $r / r$ mice injected subcutaneously over the hemicalvariae with vehicle or PTH. Shown are representative photomicrographs of sections of calvarial bone that illustrate resorptive responses to $\mathrm{PTH}$ of $+/+$ and $r / r$ mice. Bones from vehicle-injected $+/+$ mice showed a normal smooth surface of bone marrow spaces and no osteoclasts. Bones from $+/+$ mice injected with PTH demonstrated marked resorption with increased osteoclasts (arrows) in cavities with irregular surfaces (measured as bone resorption area and illustrated in Fig. 3). In contrast, the appearance of bones from the PTH-treated $r / r$ mice was similar to that of vehicle-treated $r / r$ mice, and few osteoclastic resorption spaces were found. Scale bar, $0.05 \mathrm{~mm}$. H\&E, hematoxylin and eosin; PTH, parathyroid hormone.
} 
ever sufficient genomic DNA was amplified, $+/+, r /+$, and $r / r$ animals could readily be distinguished (data not shown).

Effects of PTH on bone resorption in vivo. To measure responses of calvarial bone to PTH, we followed the procedures developed by Boyce and coworkers $(31,32)$. Synthetic human PTH(1-34) was obtained from A. Khatri (Endocrine Unit, Massachusetts General Hospital, Boston, Massachusetts, USA) and was dissolved in vehicle ( $1 \mathrm{mM} \mathrm{HCl}, 0.1 \% \mathrm{BSA})$. PTH, at $10 \mu \mathrm{g}$ in $25 \mu \mathrm{l}$ or $2 \mu \mathrm{g}$ in $10 \mu \mathrm{l}$, or vehicle in the same volume, were injected subcutaneously four times daily for 3 days, using a Hamilton syringe, into the subcutaneous tissue overlying the right side of the calvariae. After sacrifice by $\mathrm{CO}_{2}$ narcosis, calvariae were removed intact, soft tissues gently dissected, and the calvariae were fixed in $10 \%$ phosphate-buffered formalin for $24 \mathrm{~h}$ for further processing and analysis.

Tissue processing and analysis. After fixation, calvariae were decalcified in 14\% EDTA for 7-8 days and then dehydrated in graded alcohol. Calvariae were then bisected perpendicular to the sagittal suture through the central portion of the parietal bone parallel to the lambdoidal and coronal sutures and paraffin embedded. Four to six $5-\mu \mathrm{m}$-thick representative, nonconsecutive step sections were cut. The sections were routinely stained with hematoxylin and eosin (H\&E). The noninjected side was shortened after dissection to distinguish the two sides. To facilitate histomorphometric measurements, a standard length of $5=\mathrm{mm}$ of each section from the edge of the sagittal suture to the muscle insertion at the lateral border of each bone was used.

Small cavities filled with bone marrow are present within the calvariae of normal mice, and most of these are adjacent to sutures in the midline, anterior, posterior, and lateral aspects of the calvariae. After treatment with PTH and other resorption-stimulating agents, osteoclasts enlarge these cavities and extend them towards the middle portion of the parietal bones. In untreated mice, the middle of the parietal bone is typically composed of solid bone matrix, with few, if any marrow cavities. Thus, the resorptive activity after PTH treatment can be assessed quantitatively by measuring the area of these bone marrow spaces at multiple sites in the calvarial bones and comparing mean values with those in controls. The total areas of bone and marrow cavities (i.e., bone and marrow between the inner and outer periosteal surfaces within the $5 \mathrm{~mm}$ length from the sagittal suture) were measured on digitized images using the National Institutes of Health (NIH; Bethesda, Maryland, USA) Image program for the Macintosh computer (Apple Computer Inc., Cupertino, California, USA). The amount of resorptive activity was estimated by expressing the bone marrow area as a percentage of the total bone area to accommodate variations in the absolute amount of bone resorption among animals (total resorption area $\%=\Sigma$ areas of bone marrow cavity $/ \Sigma$ total bone areas $\times 100$ ). Active bone resorption was also estimated by measuring the number of osteoclasts along the interface between bone and bone marrow, expressed as a percentage of the total length of this interface (active resorption surface $\%=\Sigma$ rough crenated surface with associated osteoclasts / total length of interface between bone and marrow cavity $x$ $100)$. In some samples, the number of osteoclasts was counted within the marrow cavity and expressed as number $/ \mathrm{mm}^{2}$ of the total bone area within the $5=\mathrm{mm}$ standard length). Osteoclasts were identified by their morphology and location in scalloped lacunae, and their presence was confirmed by staining for tartrate-resistant acid phosphatase (TRAP) (33).

To reduce measurement errors, at least two of the most central sections among all sections from each sample were examined and quantified. Each area of bone resorption was digitized twice using the NIH Image program, and two readings were averaged. All measured areas of bone resorption within each section were then summed. Statistical significance was determined using ANOVA.
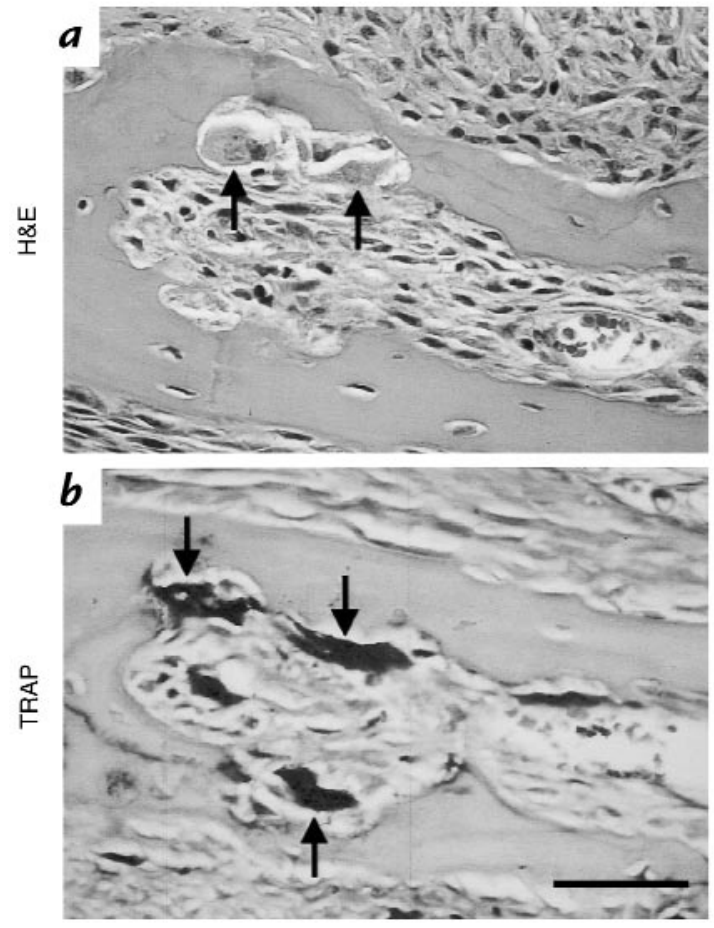

\section{Figure 2}

Presence of osteoclast-like cells, identified by TRAP staining, in calvarial bone from $+/+$ mice injected subcutaneously over the hemicalvariae with PTH. The identification of osteoclasts in the PTH-treated $+/+$ calvariae was confirmed using TRAP staining. (a) The section stained with H\&E. (b) An adjacent section stained with TRAP. Arrows indicate multinucleated osteoclasts in intracalvarial resorption spaces. Scale bar, $0.05 \mathrm{~mm}$. TRAP, tartrate-resistant acid protein.

Calcemic responses to $P T H$. To measure calcemic responses, synthetic human PTH(1-34) $(15 \mu \mathrm{g})$ or vehicle was injected once intraperitoneally in groups of $+/+$ and $r / r$ mice of different ages, and blood ionized calcium concentration, $\left[\mathrm{Ca}^{2+}\right]$, was determined with the $634 \mathrm{ISC} \mathrm{Ca}^{2+} / \mathrm{pH}$ Analyzer from Ciba-Corning Diagnostics Corp. (Medfield, Massachusetts, USA) at intervals from 0.5 up to $10 \mathrm{~h}$ after injection. Statistical significance was determined using Student's $t$ test.

In situ bybridization. Paraffin sections were used. Osteoclasts were further identified by in situ hybridization using a ${ }^{35}$ S $] \alpha-U T P 5^{\prime}$ antisense riboprobe composed of sequences in the $3^{\prime}$ untranslated region of the mouse $92-\mathrm{kDa}$ gelatinase cDNA (18), a gift from K. Tryggvason (Karolinska Institute, Stockholm, Sweden). For the mouse collagenase, we prepared an antisense $\left[{ }^{35} \mathrm{~S}\right] \alpha$-UTP $5^{\prime}$ riboprobe composed of the NcoI/AvrII sequences that cover the open reading frame through the zinc-binding site in the cDNA (16), a gift from Y. Eeckhout (University of Louvain Medical School, Brussels, Belgium). Sense riboprobes were used as controls.

\section{Results}

Effects of PTH on resorption of calvarial bone. PTH injected subcutaneously over hemicalvariae induced marked increases in bone resorption in the $+/+$ mice of different ages and different genetic background (i.e., $+/+$ mice of the C57BL and/or 129 strains and the $+/+$ progeny of $\mathrm{C} 57 \mathrm{BL} \times 129$ matings). In contrast, there was little or no bone resorption in the calvariae of the $\mathrm{r} / \mathrm{r}$ mice treated with PTH. The histological appearance of representative calvarial bone sections stained with $\mathrm{H} \& \mathrm{E}$ from mice in the different treatment groups is shown in Fig. 1. 
Resorption spaces containing blood vessels, multinucleated cells resembling osteoclasts, as well as mononucleated cells were seen in samples from $+/+$ mice injected with PTH $(\Delta)$. In contrast, the bones from the $\mathrm{r} / \mathrm{r}$ animals treated with PTH contained few resorption spaces and only rare osteoclasts, mostly located in the suture areas. Identification of the multinucleated cells in the PTHtreated $+/+$ mouse calvariae as osteoclasts was further

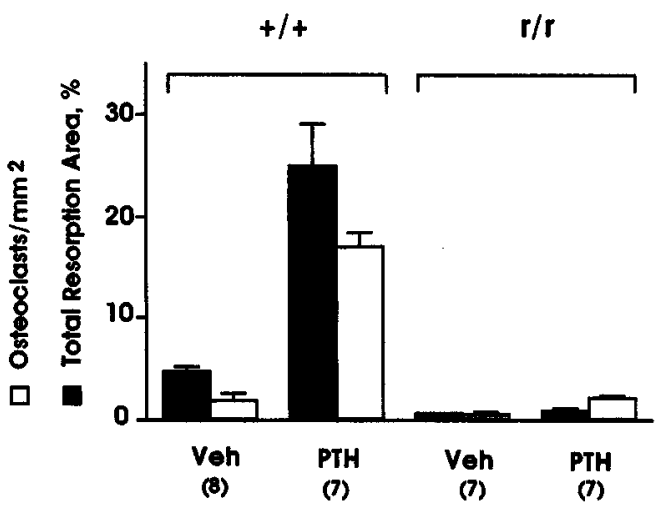

Figure 3

Changes in calvarial bone area and osteoclast number in 4-week-old $+/+$ and $r / r$ mice injected subcutaneously over the hemicalvariae with vehicle (Veh) or PTH. Black bars (means \pm SEM) indicate the bone marrow space area (total resorption area), expressed as a percentage of the total bone area in a standard length of calvarial sections. Clear bars (means \pm SEM) indicate the number of osteoclasts in the total bone area (i.e., per $\mathrm{mm}^{2}$ ). The number of mice examined are indicated in parentheses. The bone resorption area and the number of osteoclasts $/ \mathrm{mm}^{2}$ were both significantly increased after PTH injection in the $+/+$ mice $(P<0.005)$, but not in the $r / r$ mice. In contrast, resorption in response to PTH was markedly reduced, and only occasional osteoclasts were identified in calvarial bone from PTH-treated $r / r$ mice.
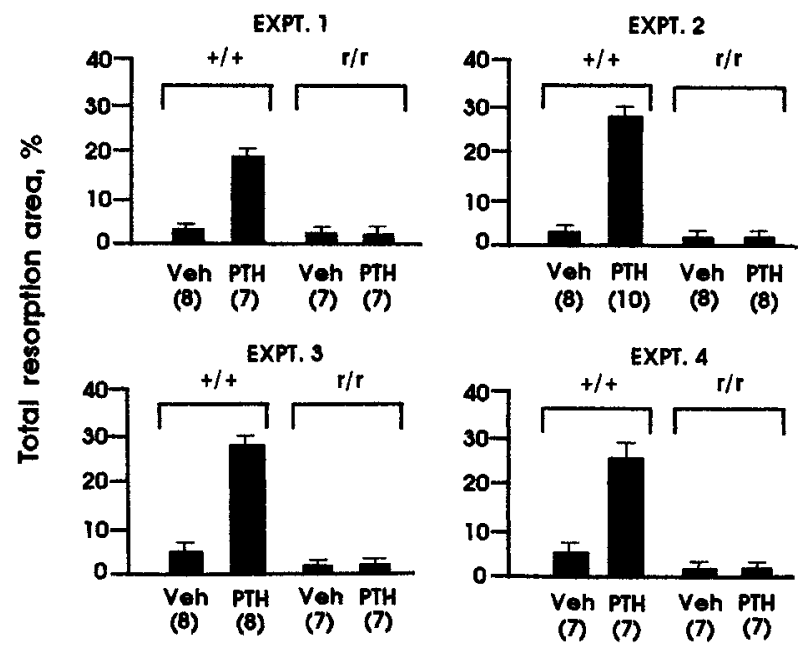

Figure 4

Changes in calvarial bone resorption area in $+/+$ and $r / r$ mice of different ages injected subcutaneously over the hemicalvariae with vehicle (Veh) or PTH. Only total bone resorption is shown as means \pm SEM. The data labeled EXPT. 1 are from the study shown in Fig. 3, using 4-week-old mice. The number of mice examined are indicated in parentheses. The age of the mice in EXPT. 2 was 4-6 weeks, and in EXPT. 3 and EXPT. 4, 9-12 months. In each of the four individual experiments, the general pattern of bone resorption in response to PTH was similar. Bone resorption in response to PTH was markedly reduced in the $r / r$ mice compared with the $+/+$ mice. supported by positive staining for TRAP, as shown in Fig. 2. Because TRAP can be found in cells other than osteoclasts, we also used in situ hybridization with the 92$\mathrm{kDa}$ gelatinase riboprobe (see below).

The resorption area as a function of total bone area was first quantitated in an experiment involving fourweek-old $+/+$ and $r / r$ mice. As shown in Fig. 3, there was a marked increase of approximately fivefold in resorption space areas in bones from $+/+$ animals treated with PTH $(P<0.005)$ and an approximately parallel increase in osteoclast number. In contrast, in the calvariae from $\mathrm{r} / \mathrm{r}$ mice, the baseline resorption area was significantly decreased $(P<0.005)$ compared with the calvariae from $+/+$ mice, and there was no significant increase after injection of PTH. The changes in calvarial bone resorption area in response to PTH injection in four separate experiments involving $+/+$ and $\mathrm{r} / \mathrm{r}$ mice of different ages are summarized in Fig. 4. In all experiments, there were significant bone resorptive responses to $\mathrm{PTH}$ in $+/+$ mice but no detectable responses in $\mathrm{r} / \mathrm{r}$ mice.

MMP gene expression using in situ bybridization. Because there was no detectable osteoclastic bone resorption in response to $\mathrm{PTH}$ in the $\mathrm{r} / \mathrm{r}$ mice, it was important to demonstrate that other cellular responses to PTH were intact, particularly enhancement of collagenase (MMP13) gene expression $(14,21)$. Using in situ hybridization in $+/+$ mice injected with PTH in vivo, we found that in the intracalvarial resorption spaces, the nonosteoclastic cells strongly expressed the collagenase gene, whereas there was no detectable expression of collagenase in osteoclasts (Fig. 5). The most intense expression of the collagenase gene in the resorption spaces was in those mononucleated cells adjacent to the osteoclasts and close to the bone surfaces. The latter TRAP-negative cells were not further identified but, based on their location within the resorption areas, they could be osteoblasts, stromal fibroblasts, or monocyte/macrophages. In contrast, the $92-\mathrm{kDa}$ gelatinase was expressed most intensely in the multinucleated, TRAP-positive osteoclasts. Because the area of these resorption spaces was small in bones from the $\mathrm{r} / \mathrm{r}$ mice and osteoclasts were rare in the basal state, and their number was not significantly increased by PTH, we examined the response to PTH injection of cells in the periosteum (Fig. 6). In calvariae from $+/+$ as well as $r / r$ mice injected with PTH, periosteal cells, particularly in the osteoblastic layer, strongly expressed collagenase, as analyzed by in situ hybridization. There was little expression of collagenase, however, in periosteal cells in calvariae from $+/+$ or $r / r$ mice injected only with vehicle. Thus, although the $\mathrm{r} / \mathrm{r}$ mice were resistant to the effects of $\mathrm{PTH}$ in inducing osteoclastic bone resorption, effects of PTH in stimulating collagenase expression in osteoblasts were intact in the $\mathrm{r} / \mathrm{r}$ mice.

Calcemic responses top PTH in $+/+$ and $r / r$ mice. Because PTH did not stimulate osteoclastic bone resorption in the $\mathrm{r} / \mathrm{r}$ mice, we asked whether PTH could nevertheless increase circulating calcium levels in these animals. PTH was given intraperitoneally in a single dose of $15 \mu \mathrm{g} / 30 \mathrm{~g}$ body weight to $\mathrm{r} / \mathrm{r}$ and $+/+$ mice, and blood ionized calcium concentration, $\left[\mathrm{Ca}^{2+}\right]$, was measured at intervals as shown for the first calcemia experiment in Fig. 7. In the $+/+$ mice, PTH increased blood $\left[\mathrm{Ca}^{2+}\right]$ by $\sim 0.2 \mathrm{mM}$ by one 

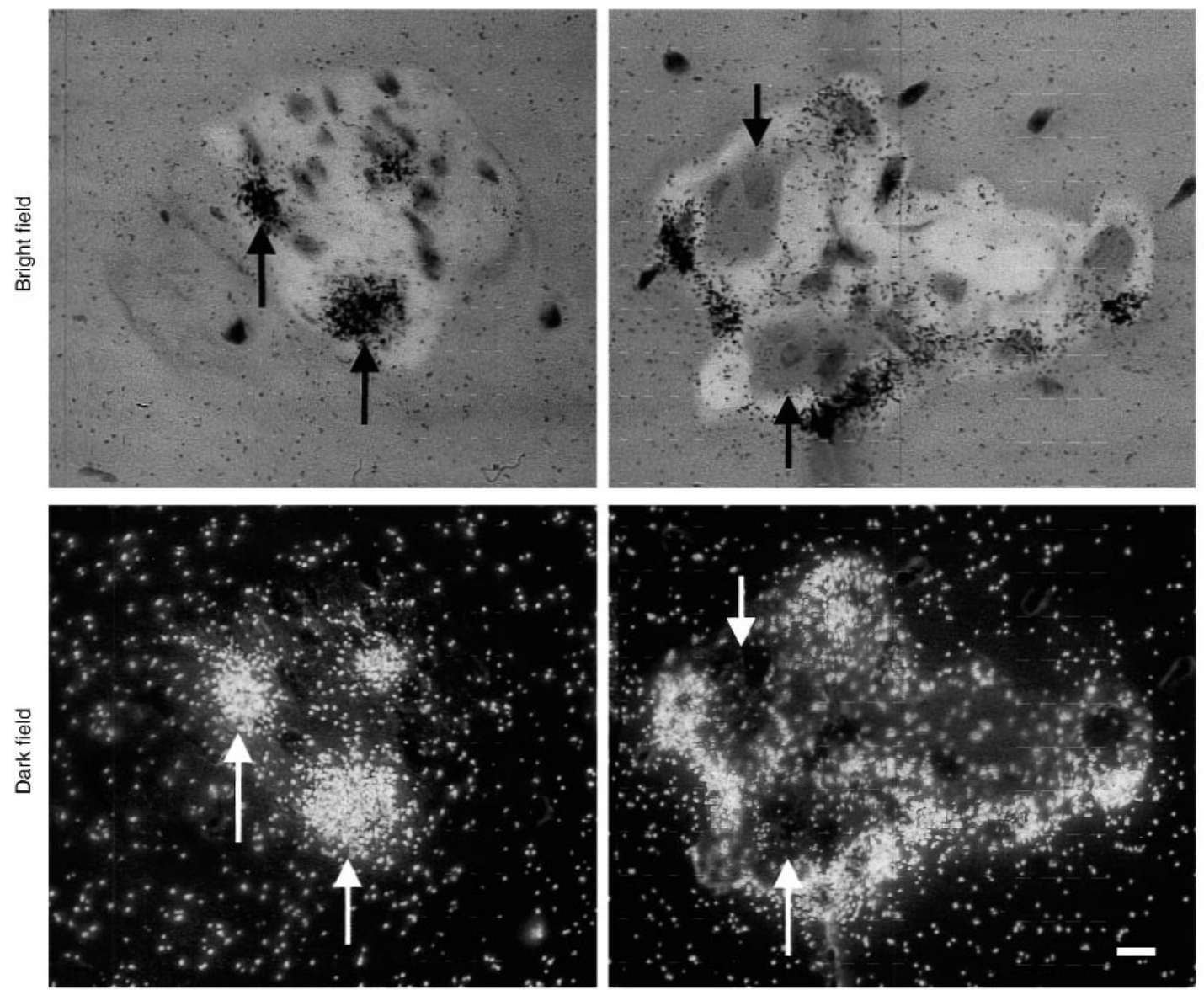

\section{Figure 5}

In situ hybridization, using collagenase and $92-\mathrm{kDa}$ gelatinase riboprobes, of the resorption areas in calvarial bone from $+/+$ mice injected subcutaneously over the hemicalvariae with PTH. Shown are calvariae from +/+ mice injected with PTH. As can be seen in sections visualized using dark field and bright field, the $92-\mathrm{kDa}$ gelatinase was strongly expressed in osteoclasts but weakly expressed in nonosteoclastic surrounding cells. In contrast, collagenase was expressed in cells other than osteoclasts and the signal was most intense in cells adjacent to the osteoclasts within the intracortical resorption spaces. Arrows indicate periosteneum. Scale bar, $0.01 \mathrm{~mm}$.

to two hours after injection, and $\left[\mathrm{Ca}^{2+}\right]$ was still elevated at 10 hours after injection. In contrast, as is also shown in Fig. 7 , in the $\mathrm{r} / \mathrm{r}$ mice, the peak rise in $\left[\mathrm{Ca}^{2+}\right]$ was significantly blunted compared with the $+/+$ mice (only $\sim 0.08$ $\mathrm{mM}$ above baseline) and was at control levels by three hours after injection. In the $\mathrm{r} / \mathrm{r}$ mice, the peak $\Delta\left[\mathrm{Ca}^{2+}\right]$ at one to three hours after injection of PTH was $0.056 \pm$ 0.010 (SEM) $\mathrm{mM}$ compared with $0.169 \pm 0.025 \mathrm{mM}$ in $+/+$ mice $(P<0.001)$. In the second calcemia experiment (not shown), the peak $\Delta\left[\mathrm{Ca}^{2+}\right]$ at one to three hours after injection of PTH in $\mathrm{r} / \mathrm{r}$ mice was $0.061 \pm 0.009 \mathrm{mM}$ compared with $0.186 \pm 0.044 \mathrm{mM}$ in $+/+$ mice $(P<0.001)$. Because both $+/+$ C57BL and 129 strain mice responded to PTH with an increase in $\left[\mathrm{Ca}^{2+}\right]$ of similar magnitude to that shown in Fig. 7 (data not shown), it is unlikely that different genetic backgrounds account for the differences in calcemic responses of $\mathrm{r} / \mathrm{r}$ and $+/+$ mice observed here.

\section{Discussion}

We report here that the homozygous Col1a $1^{\mathrm{tml} J a e}$ mice (30) that are resistant to collagenase cleavage of type I collagen have a markedly blunted response to the boneresorptive effects of PTH. These mice have a targeted mutation $(29,30)$ in Col1a1 that encodes amino acid substitutions in the helical region of the $\alpha 1(\mathrm{I})$ chain around the collagenase cleavage site from $\mathrm{P}_{2}$ through $\mathrm{P}_{8}$ ' (residues 774-783). We chose to target the substrate rather than the enzyme(s) because of the potential redundancy in collagenase genes in the mouse analogous to that in humans, although at the present time, only the genes homologous to human collagenase- 2 (MMP-8) (33) and human collagenase-3 (MMP-13) (17) have been identified in the mouse. Neither the $\alpha 1$ (I) chain nor the $\alpha 2$ (I) chain of the heterotrimeric type I collagen extracted from skin, bone, and tendon of the Colla $1^{\text {tml Jae }}$ mice that carry the mutation $(r)$ on both alleles $(r / r)$ was cleaved by rat or mouse collagenase (now called MMP-13) or human fibroblast collagenase (MMP1) at what was previously considered to be the single cleavage site at Gly775/Ile776 $\left(\mathrm{P}_{1} / \mathrm{P}_{1}{ }^{\prime}\right)$ in the helical domain in the $\alpha 1(\mathrm{I})$ chain $(34,35)$.

Although embryonic development in the $\mathrm{r} / \mathrm{r}$ mice appeared to be normal, we have now observed that after as early as two to four weeks of age, the $\mathrm{r} / \mathrm{r}$ mice begin to display abnormalities such as thickened skin with patchy hair loss, joint contractures, and nodules containing 

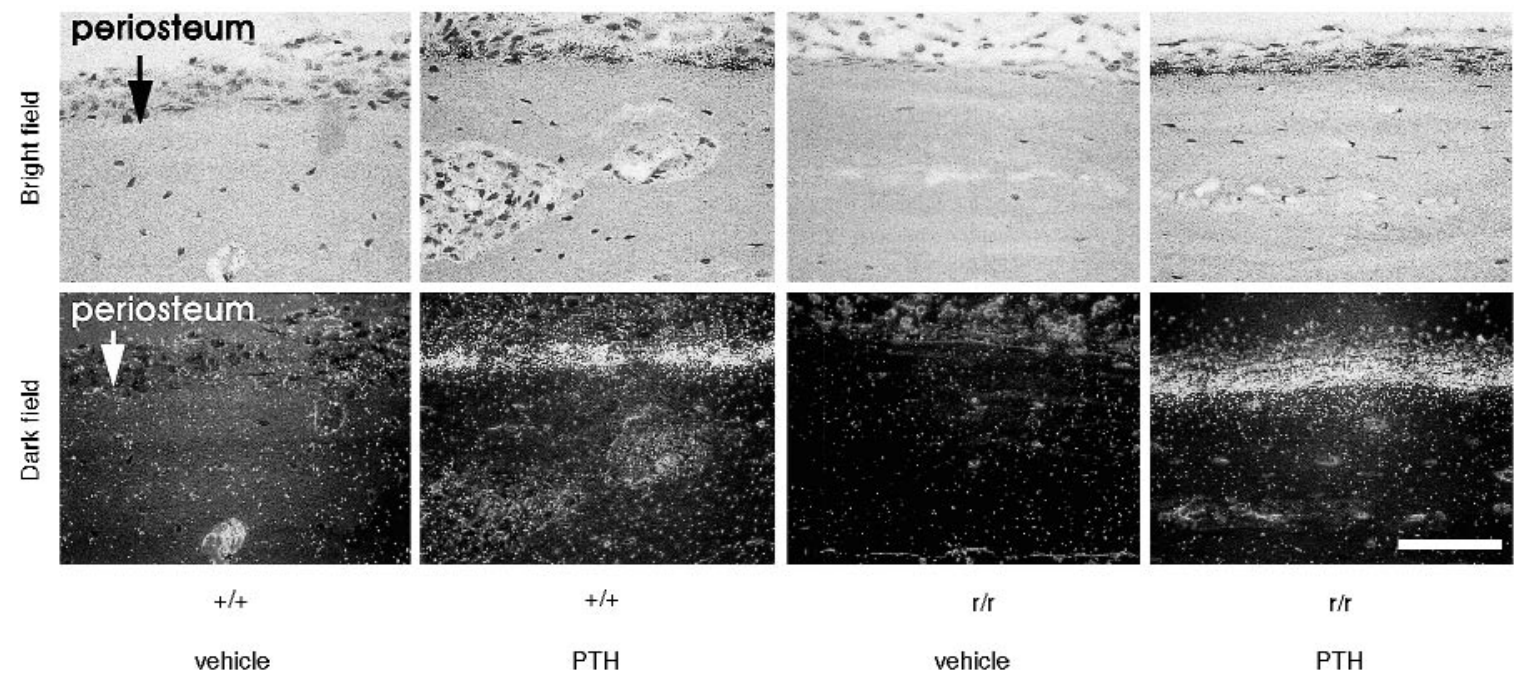

Figure 6

In situ hybridization, using a collagenase riboprobe, of calvarial bone from $+/+$ and $r / r$ mice injected subcutaneously over the hemicalvariae with vehicle or PTH. The outer (subcutaneous) side is shown. Sections were hybridized with the antisense collagenase riboprobe and were visualized using bright field (top) and dark field (bottom). Arrows indicate the periosteum. No hybridization with the collagenase riboprobe was detected in the periosteum in calvariae from vehicle-treated $+/+$ mice or vehicle-treated $r / r$ mice. In calvariae from both $+/+$ and $r / r$ mice, levels of collagenase mRNA in periosteal osteoblasts were markedly increased after PTH injection. No signal was observed in samples hybridized with the collagenase sense riboprobe (not shown). Scale bar, $0.05 \mathrm{~mm}$.

type I collagen in the uterus of postpregnant females (30). In skin from $r / r$ mice, histological examination with $\mathrm{H} \& \mathrm{E}$ and trichrome staining shows a remarkable increase in collagen extending through to the deep dermis (30). We also observed bony deformities, particularly of long bones, with increased deposition of woven bone; these lesions could possibly have resulted from healing fractures as well (Zhao, W., and Krane, S.M., manuscript in preparation). Subsequently, we observed that highly purified rat collagenase $(97 \%$ amino acid sequence identity with the mouse; ref. 16), which did not cleave at the helical site in the $\mathrm{r} / \mathrm{r}$ collagen, did cleave at an additional site between a Gly/Val in the $\mathrm{NH}_{2}$-telopeptide (30). We later determined (36) that the capacity to cleave type I collagen in the $\mathrm{NH}_{2}$-telopeptide is a property of these mouse (16) and rat collagenases, which have $\sim 97 \%$ amino acid sequence identity with each other but only $\sim 50 \%$ amino acid sequence identity with human MMP-1 (16). We proposed $(30,36)$ that the $\mathrm{NH}_{2}$-telopeptide cleavage activity of the rodent-type collagenases that are homologous with human MMP-13 might be sufficient for type I collagen cleavage during embryonic development, but that later in life during phases of intense resorption and/or after the collagen is covalently crosslinked, helical cleavage may be required.

The decrease in bone resorption and the paucity of osteoclasts in response to PTH in the $\mathrm{r} / \mathrm{r}$ mice whose collagen cannot be cleaved at the helical locus could have several possible explanations. First, as mentioned previously, there are indications that osteoblasts, when exposed to concentrations of PTH sufficient to induce bone resorption, start to produce collagenase and decrease synthesis of collagen (21). It has been suggested, based on assessments of osteoclast attachment and bone pit formation in in vitro assays, that collagenase produced by osteoblasts in remodeling bone acts on a layer of hypomineralized collagen on bone surfaces (28) to permit osteoclasts to attach and then resorb bone by mechanisms utilizing other proteinases (37-40). Thus, osteoblasts and/or related mesenchymal cells, such as marrow stromal fibroblasts, that at some stage function to synthesize the ECM of bone, also could function at another stage (in bone resorption) by preparing the matrix for osteoclastic attachment and subsequent degradation by proteinases such as cathepsins that act at the acid $\mathrm{pH}$ in the unique environment adjacent to the ruffled border (37-40). Second, it has been shown by Pfeilschifter and Mundy (41) and Bonewald et al. (42) that when osteoclasts resorb bone, a number of cytokines/growth factors previously sequestered and trapped in the bone matrix are released, and, with respect to TGF- $\beta$, latent forms of the ligand are activated as well. It has been proposed further that these (active) ligands then act on osteoblasts and their precursors to stimulate bone formation. In an analogous manner, when osteoblasts produce collagenase, an enzyme with a relatively limited proteinase specificity that can act to degrade partially mineralized surface bone collagen, collagenase might then release biologically active ligands previously trapped in the matrix that could stimulate the generation and activity of osteoclasts. Third, fragments of type I collagen produced by the action of collagenase might themselves be biologically active. Fourth, it has been shown that in the course of normal bone remodeling osteoclasts undergo apoptosis (43-45). Release of biologically active peptides through effects on bone of osteoblast-derived collagenase might also function to prevent apoptosis. Therefore, inadequate collagenase digestion of the mutated type I collagen in bones from the $\mathrm{r} / \mathrm{r}$ mice and failure to release these critical sequestered ligands could result in osteoclast apoptosis. An additional possibility is that the adherence of 
osteoclasts to bone surfaces prepared by collagenase itself generates an anti-apoptotic signal. Failure of collagenase to cleave bone type I collagen in the $\mathrm{r} / \mathrm{r}$ mice might therefore indirectly abrogate this antiapoptotic signal. Some evidence to support this hypothesis follows. It has been shown that cells can bind to type I collagen through the $\alpha 2 \beta 1$ integrin (46) and that "liganding" $\alpha 2 \beta 1$ induces collagenase gene transcription followed by secretion and activation of latent (pro)enzyme $(47,48)$. Proteolytic attack on type I collagen can then result in unwinding of the cleaved ends to reveal a cryptic binding site(s) for the $\alpha v \beta 3$ integrin (48). Liganding this cryptic binding site by the $\alpha v \beta 3$ integrin then promotes a phosphatidylinositol 3-kinase (PI-3 kinase)-mediated adhesion-dependent survival signal necessary for cells to normally progress through the cell cycle. Failure to bind through $\alpha v \beta 3$ results in apoptosis, mediated by $\mathrm{p} 53$ and p $21^{\text {WAF1/CPI1 }}(49,50)$. Thus, $\alpha v \beta 3$ integrin antagonists suppress $\mathrm{p} 53$ activity and block p $21^{\mathrm{WAF} 1 / \mathrm{CPI} 1}$ expression and increase the ratio of bcl-2/bax, whereas $\alpha v \beta 3$ antagonists activate $\mathrm{p} 53$ and increase $\mathrm{p} 21^{\mathrm{WAF} 1 / \mathrm{CPI} 1}$ expression and decrease the ratio of bcl-2/bax $(49,50)$. Other observations pertain to these considerations. Keratinocytes bind to type I collagen through the $\alpha 2 \beta 1$ integrin resulting in activation of MMP-1 expression (47). Collagenase is then secreted and activated and the type I collagen substrate at least partially cleaved, events essential for migration of the keratinocytes (47). These cells also activate collagenase expression using a type I collagen substrate prepared from the $\mathrm{r} / \mathrm{r}$ mice, but they do not migrate, presumably because the collagen cannot be cleaved at the helical locus. Osteoclasts adhere to undenatured type I collagen through the $\alpha 2 \beta 1$ integrin, but to denatured collagen through $\alpha v \beta 3$ (51). Recognition by $\alpha v \beta 3$ of sites in denatured collagen could be equivalent to a site generated by collagenase cleavage in the helical region that then results in unwinding (denaturation) of the cut ends, and collagenase-generated type I collagen fragments can activate osteoclasts to resorb bone (52). Furthermore, synthetic peptidomimetic antagonists of $\alpha v \beta 3$ integrin inhibit bone resorption in vivo (53). One of the mechanisms of this inhibition of osteoclast activity, as well as osteoclast generation, could involve induction of osteoclast apoptosis, an effect observed by one of us when murine osteoclasts were treated with RGD (Arg-Gly-Asp) peptide-based inhibitors (54).

Whatever the mechanism, it is clear from these studies that induction of bone resorption by PTH is markedly inhibited in the $\mathrm{r} / \mathrm{r}$ mice. Collagenase cleavage at the helical locus in type I collagen appears to be essential for osteoclastic resorption. Because embryonic development is nor$\mathrm{mal}$ in the $\mathrm{r} / \mathrm{r}$ mice, implying that bone resorption during the early phase of life can still occur, it is possible that cleavage by collagenase at the $\mathrm{NH}_{2}$-telopeptide site before formation of stable intermolecular cross-links could be sufficient at this stage, although $\mathrm{NH}_{2}$-telopeptide cleavage has only been demonstrated in vitro $(30,36)$. Alternatively, bone trabeculae, formed in the primary and secondary spongiosa during intrauterine and neonatal development, may be laid down and removed so rapidly that they do not become coated with the layer of hypomineralized matrix observed on bone surfaces of mature animals.

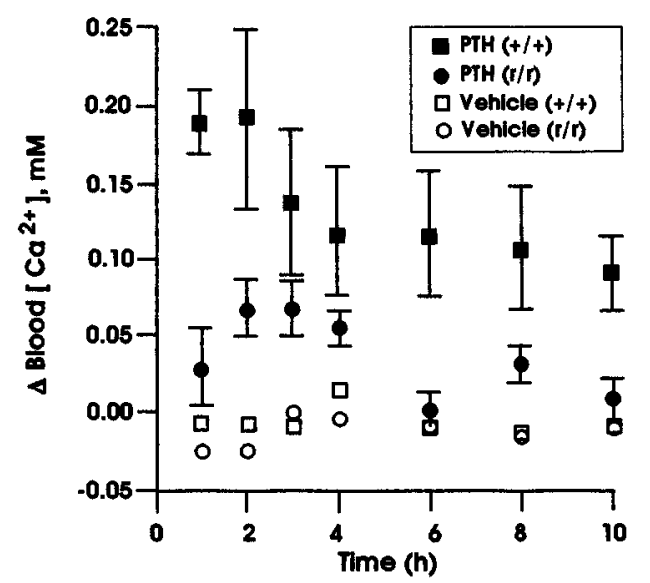

Figure 7

Changes in blood $\left[\mathrm{Ca}^{2+}\right]$ in $+/+$ and $r / r$ mice injected intraperitoneally with vehicle or PTH. The calcemic response after a single intraperitoneal injection of vehicle or $15 \mu \mathrm{g}$ PTH in $+/+$ and $r / r$ mice is shown as described for the first calcemia experiment. The change in blood ionized calcium levels, $\Delta$ blood $\left[\mathrm{Ca}^{2+}\right]$, at intervals from 0.5 to $10 \mathrm{~h}$ after PTH injection (shown as means \pm SEM) is depicted on the vertical axis. Peak levels of $\Delta$ blood $\left[\mathrm{Ca}^{2+}\right]$ were observed within the first 1-3 h after PTH injection in the $+/+$ mice (filled circles). As described in the text, peak levels of $\Delta$ blood $\left[\mathrm{Ca}^{2+}\right]$ after PTH injection in the $\mathrm{r} / \mathrm{r}$ mice were significantly lower than in the $+/+$ mice (filled squares).

\section{Acknowledgments}

This work was supported by grants AR-03564, AR-07258, and AR-44855 from the National Institutes of Health.

1. Potts, J.T., Jr., and Jüppner, H. 1997. Parathyroid hormone and parathyroid hormone-related peptide in calcium homeostasis, bone metabolism, and bone development: the proteins, their genes, and receptors. In Metabolic bone disease and clinically related disorders. L.V. Avioli and S.M. Krane, editors. Academic Press. San Diego, CA. 51-94.

2. Suda, T., Takahashi, N., and Martin, T.J. 1992. Modulation of osteoclast differentiation. Endocr. Rev. 13:66-80.

3. Yasuda, H., et al. 1998. Osteoclast differentiation factor is a ligand for osteoprotogerin/osteoclastogenesis-inhibitory factor and is identical to TRANCE/RANKL. Proc. Natl. Acad. Sci. USA. 95:3597-3602.

4. Gross, J., and Lapière, C.M. 1962. Collagenolytic activity in amphibian tissues: a tissue culture assay. Proc. Natl. Acad. Sci. USA. 48:1014-1022.

5. Walker, D.G., Lapière, C.M., and Gross, J. 1964. A collagenolytic factor in rat bone promoted by parathyroid extract. Biochem. Biophys. Res. Commun. 15:397-402.

6. Krane, S.M. 1975. Skeletal remodeling and metabolic bone disease. In Calcium-regulating hormones. R.V. Talmage, M. Owen, and J.A. Parsons, editors. Excerpta Medica. Amsterdam, The Netherlands. 57-65.

7. Rasmussen, H., Arnaud, C., and Hawker, C. 1964. Actinomycin D and the response to parathyroid hormone. Science. 144:1019-1021.

8. Tashjian, A.H., Jr., Ontjes, D.A., and Goodfriend, T.L. 1964. Mechanism of parathyroid hormone action. Effects of actinomycin D on hormonestimulated ion movement in vivo and in vitro. Biochem. Biophys. Res. Commun. 16:209-215.

9. Kunin, A.S., and Krane, S.M. 1965. Inhibition by puromycin of the calcium-mobilizing activity of parathyroid extract. Endocrinology. 76:343-344

10. Sakamoto, S., Sakamoto, M., Goldhaber, P., and Glimcher, M.J. 1975. Collagenase and bone resorption: isolation of collagenase from culture medium containing serum after stimulation of bone resorption by addition of parathyroid hormone extract. Biochem. Biophys. Res. Commun. 63:172-178.

11. Sakamoto, S., Sakamoto, M., Goldhaber, P., and Glimcher, M.J. 1975. Studies on the interaction between heparin and mouse bone collagenase. Biochim. Biophys. Acta. 385:41-50.

12. Sakamoto, S., Sakamoto, M., Goldhaber, P., and Glimcher, M.J. 1978. Mouse bone collagenase. Purification of the enzyme by heparin-substituted Sepharose-4B affinity chromatography and preparation of specific antibody to the enzyme. Arch. Biochem. Biophys. 188:438-449.

13. Sakamoto, S., Sakamoto, M., and Horton, J.E. 1984. Evidence that col- 
lagenase is involved in the mechanisms of bone resorption stimulated with parathyroid hormone: a study in two different bone culture systems. In Endocrine control of bone and calcium metabolism. D.V. Cohn, T. Fujita, J.T. Potts, Jr., and R.V. Talmage, editors. Excerpta Medica. Amsterdam, The Netherlands. 140-143

14. Partridge, N.C., et al. 1987. Hormonal regulation of the production of collagenase and a collagenase inhibitor activity by rat osteogenic sarcoma cells. Endocrinology. 120:1956-1962.

15. Quinn, C.O., et al. 1990. Rat collagenase. Cloning, amino acid sequence comparison, and parathyroid hormone regulation in osteoblastic cells. J. Biol. Chem. 265:22342-22347.

16. Henriet, P., Rousseau, G.G., and Eeckhout, Y. 1992. Cloning and sequencing of mouse collagenase cDNA. Divergence of mouse and rat collagenases from the other mammalian collagenases. FEBS Lett. 310:175-178.

17. Freije, J.M.P., et al. 1994. Molecular cloning and expression of collagenase-3, a novel human matrix metalloproteinase produced by breast carcinomas. J. Biol. Chem. 269:16766-16773.

18. Reponen, P., Sahlberg, C., Munaut, C., Thesleff, I., and Tryggvason, K. 1994. High expression of $92-k D$ type IV collagenase (gelatinase B) in the osteoclast lineage during mouse development. J. Cell Biol. 124:1091-1102.

19. Sato, T., et al. 1997. Identification of the membrane-type matrix metalloproteinase MT1-MMP in osteoclasts. J. Cell Sci. 110:589-596.

20. Delaissé, J.M., et al. 1993. (Pro)collagenase (matrix metalloproteinase-1) is present in rodent osteoclasts and in the underlying bone-resorbing compartment. J. Cell Sci. 106:1071-1082.

21. Scott, D.K., Brakenhoff, K.D., Clohisy, J.C., Quinn, C.O., and Partridge, N.C 1992. Parathyroid hormone induces transcription of collagenase in rat osteoblastic cells by a mechanism using cyclic adenosine 3 ', $5^{\prime}$-monophosphate and requiring protein synthesis. Mol. Endocrinol. 6:2153-2159.

22. Mattot, V., et al. 1995. Expression of interstitial collagenase is restricted to skeletal tissue during mouse embryogenesis. J. Cell Sci. 108:529-535

23. Fuller, K., and Chambers, T.J. 1995. Localisation of mRNA for collagenase in osteocytic, bone surface and chondrocytic cells but not osteoclasts. J. Cell Sci. 108:2221-2230.

24. Gack, S., et al. 1995. Expression of interstitial collagenase during skeletal development of the mouse is restricted to osteoblast-like cells and hypertrophic chondrocytes. Cell Growth Differ. 6:759-767.

25. Meikle, M.C., et al. 1992. Human osteoblasts in culture synthesize collagenase and other matrix metalloproteinases in response to osteotropic hormones and cytokines. J. Cell Sci. 103:1093-1099.

26. Lanske, B., et al. 1998. The parathyroid hormone (PTH)/PTH-related peptide receptor mediates actions of both ligands in murine bone. Endocrinology. 139:5194-5204.

27. Lanske, B., et al. 1996. PTH/PTHrP receptor in early development and Indian hedgehog-regulated bone growth. Science. 273:663-666.

28. Chambers, T.J., Darby, J.A., and Fuller, K. 1985. Mammalian collagenase predisposes bone surfaces to osteoclastic resorption. Cell Tissue Res. 421:671-675.

29. Wu, H., et al. 1990. Generation of collagenase-resistant collagen by sitedirected mutagenesis of murine pro 1 (I) collagen gene. Proc. Natl. Acad. Sci. USA. 87:5888-5892.

30. Liu, X., et al. 1995. A targeted mutation at the known collagenase cleavage site in mouse type I collagen impairs tissue remodeling. J. Cell Biol. 130:227-237

31. Boyce, B.F., Aufdemorte, T.B., Ross Garrett, I., Yates, A.J.P., and Mundy, G.R. 1989. Effects of interleukin-1 on bone turnover in normal mice. Endocrinology. 125:1142-1150.

32. Yates, A.J.P., et al. 1988. Effects of a synthetic peptide of a parathyroid hormone-related protein on calcium homeostasis, renal tubular calcium reabsorption, and bone metabolism in vivo and in vitro in rodents. J. Clin. Invest. 81:932-938.

33. Lawson, N.D., Khanna-Gupta, A., and Berliner, N. 1998. Isolation and characterization of the cDNA for mouse neutrophil collagenase: demonstration of shared negative regulatory pathways for neutrophil secondary granule protein gene expression. Blood. 91:2517-2524.

34. Gross, J. 1981. An essay on biological degradation of collagen. In Cell biology of the extracellular matrix. E.D. Hay, editor. Plenum Press. New York, NY. 217-258.

35. Birkedal-Hansen, H., et al. 1993. Matrix metalloproteinases: a review. Crit. Rev. Oral. Biol. Med. 4:197-250.

36. Krane, S.M., et al. 1996. Different collagenase gene products have different roles in degradation of type I collagen. J. Biol. Chem. 271:28509-28515.

37. Blair, H.C., et al. 1993. Extracellular-matrix degradation at acid pH. Avian osteoclast acid collagenase isolation and characterization. Biochem. J. 290:873-884.

38. Burleigh, M.C. 1977. Degradation of collagen by non-specific proteinases. In Proteinases in mammalian cells and tissues. A.J. Barrett, editor. Elsevier Science. Amsterdam, The Netherlands. 285-309.

39. Drake, F.H., et al. 1996. Cathepsin K, but not cathepsin B, L, or S, is abundantly expressed in human osteoclasts. J. Biol. Chem. 271:12511-12516.

40. Bossard, M.J., et al. 1996. Proteolytic activity of human osteoclast cathep$\sin \mathrm{K}$. Expression, purification, activation, and substrate identification. J. Biol. Chem. 271:12517-12524.

41. Pfeilschifter, J., and Mundy, G.R. 1987. Modulation of type $\beta$ transforming growth factor activity in bone cultures by osteotropic hormones. Proc. Natl. Acad. Sci. USA. 84:2024-2028.

42. Bonewald, L.F., et al. 1997. Effects of retinol on activation of latent transforming growth factor- $\beta$ by isolated osteoclasts. Endocrinology. 138:657-666.

43. Hughes, D.E., et al. 1995. Bisphosphonates promote apoptosis in murine osteoclasts in vitro and in vivo. J. Bone Miner. Res. 10:1478-1487.

44. Hughes, D.E., et al. 1996. Estrogen promotes apoptosis of murine osteoclasts mediated by TGF- $\beta$. Nat. Med. 2:1132-1136.

45. Hughes, D.E., and Boyce, B.F. 1997. Apoptosis in bone physiology and disease. Mol. Pathol. 50:132-137.

46. Staatz, W.D., Rajpara, S.M., Wayner, E.A., Carter, W.G., and Santaro, S.A. 1989. The membrane glycoprotein Ia-IIa (VLA-2) complex mediates the $\mathrm{Mg}^{++}$-dependent adhesion of platelets to collagen. J. Cell Biol. 108:1917-1924.

47. Pilcher, B.K., et al. 1997. The activity of collagenase-1 is required for keratinocyte migration on type I collagen matrix. J. Cell Biol. 137:1445-1457.

48. Montgomery, A.M.P., Reisfeld, R.A., and Cheresh, D.A. 1994. Integrin $\alpha v \beta 3$ rescues melanoma cells from apoptosis in three-dimensional dermal collagen. Proc. Natl. Acad. Sci. USA. 91:8856-8860.

49. Brooks, P.C., et al. 1996. Localization of matrix metalloproteinase MMP2 to the surface of invasive cells by interaction with integrin $\alpha v \beta 3$. Cell. 85:683-693.

50. Strömblad, S., Becker, J.C., Yebra, M., Brooks, P.C., and Cheresh, D.A. 1996. Suppression of P53 activity and $\mathrm{p} 21^{\mathrm{WAF} 1 / \mathrm{CIP} 1}$ expression by vascular integrin $\alpha v \beta 3$. J. Clin. Invest. 98:426-433.

51. Helfrich, M., et al. 1996. $\beta 1$ integrins and osteoclast function: involvement in collagen recognition and bone resorption. Bone. 19:317-328.

52. Holliday, L.S., et al. 1997. Initiation of osteoclastic bone resorption by interstitial collagenase. J. Biol. Chem. 272:22053-22058.

53. Engleman, V.W., et al. 1997. A peptidomimetic antagonist of the $\alpha v \beta 3$ integrin inhibits bone resorption and prevents osteoporosis in vivo. $J$. Clin. Invest. 99:2284-2292.

54. Rani, S., Xing, L., Chen, H., Dai, A., and Boyce, B.F. 1997. Phosphatidyl inositol 3-kinase activity is required for bone resorption and osteoclast survival in vitro. J. Bone Miner. Res. 12:S420. (Abstr.) 